\title{
Holocene climate change and its context for the future
}

\author{
Shaun A. Marcott ${ }^{1}$ and Jeremy D. Shakun ${ }^{2}$ \\ Mount Hood, USA, 13-16 October 2014
}

The Holocene, which covers the last 11,700 years including the entire time span of human civilization, stands out as an interval of relative climate stability. A major goal of the paleoclimate community has been to develop a longer-term perspective on climate change to understand natural variability and provide con text for future warming, which model projections indicate will substantially exceed even the warmest Holocene conditions (Fig. 1b). Major efforts by PAGES working groups to synthesize and analyze global paleoclimate records and model simulations of the late Quaternary have mostly focused on the Common Era of the past two millennia (PAGES 2k), the last deglaciation (SynTraCE-21), and past interglacials (PIGS), with relatively less attention paid to the transient evolution of the Holocene. Given that the Holocene is the closest analog for today's climate state and covered by abundant proxy data, coordinated scrutiny of the Earth System over this timeframe should add important information regarding future climate change.

To better define both the short and long-term goals of the scientific community working on reconstructing and modeling Holocene climate, a meeting was held at Timberline Lodge at Mount Hood, Oregon. The meeting focused primarily on three themes: regional and global climate trends, variability in space and time, and data-model comparison.

\section{Trends}

As highlighted in Marcott et al. (2013) and Liu et al. (2014), a data-model disparity exists for global surface temperature during the Holocene that is not apparent for the last deglaciation, with proxies recording a longterm cooling and models simulating a warming (Fig. 1a). This "conundrum" was distilled to either relating to seasonal biases in the data, incomplete forcings, or insufficiently sensitive feedbacks in the models, or a combination of these. Seasonal biases in paleoclimate proxies pose a major challenge for reconstructing annual temperatures and comparing unlike datasets (e.g. Mix 2006), particularly during the Holocene when seasonal insolation changes were strong compared to other forcings that act across the year. Model simulations are likewise challenged by initiating glacial inceptions from insolation forcing and are limited by some weakly constrained forcing inputs, such as volcanic and solar activity. Resolving the Holocene temperature conundrum is important for understanding the forcing-response mechanisms during the current interglacial and for putting present and future climate into context, as the global temperature trend dictates to what extent today's earth system has already exited the Holocene range (Fig. 1b).

\section{Variability}

Temperature, precipitation, and glacier variability at sub-millennial frequencies and in multiple regions was also discussed. Given the relatively small changes in climate during the Holocene, differentiating a meaningful climate signal from proxy or local noise was highlighted as a critical goal for accurately reconstructing Holocene variability. This issue is central to comparisons between data and model results, which currently disagree over the spectrum of regional variability. Models tend to suppress the regional-scale variability seen by proxies at multi-decadal and longer periods (Fig. 1c). This discrepancy suggests that models may not generate enough low frequency internal variability, thus limiting their ability to produce accurate simulations of climate at longer time scales (Laepple and Huybers 2014).

\section{Proposing a PAGES 12k Working Group} To move forward, a PAGES 12k Holocene working group was agreed to be a useful bridge between the existing PAGES $2 \mathrm{k}$ project and previous efforts focusing on the deglaciation. The focus should be on both temperature and hydroclimate changes across the Holocene and include independent modeling and data analysis efforts. Forward modeling will be an important link between the modeling and proxy communities that will enable true data-model comparisons. The initial phase of the working group should focus on developing a Holocene database, first synthesizing existing compilations, and then incorporating remaining data. Community involvement and potential crowd sourcing should be encouraged to finalize the database and maximize its analysis, leading to a series of synthesis products. To run and maintain such an effort requires that dedicated personnel be supported. This could include a well-versed postdoc(s) who would lead the initial phase of the project and help steer the early scientific objectives.

\section{ACKNOWLEDGEMENTS}

The meeting was sponsored by the US National Science Foundation (\#1449148) and PAGES. We thank T. Kiefer, T. Laepple, Z. Liu, H. Wanner, J. Zhu, and all of the workshop participants for assistance.

\section{AFFILIATIONS}

'Department of Geoscience, University of WisconsinMadison, USA

2Department of Earth and Environmental Sciences, Boston College, USA

\section{CONTACT}

Shaun A. Marcott: smarcott@wisc.edu REFERENCES

Collins M et al. (2013) In: Stocker TF et al. (Eds.) Climate Change 2013 - The Physical Science Basis, Cambridge University Press, 1029-1136

Laepple T, Huybers P (2014) PNAS 111: 16682-16687 Liu et al. (2014) PNAS: E3501-E3505

Marcott et al. (2013) Science 339: 1198-1201 Mix AC (2006) Quat Sci Rev 25: 1147-1149 PAGES 2k Consortium (2013) Nat Geosci 6: 339-346 Shakun et al. (2012) Nature 484: 49-54
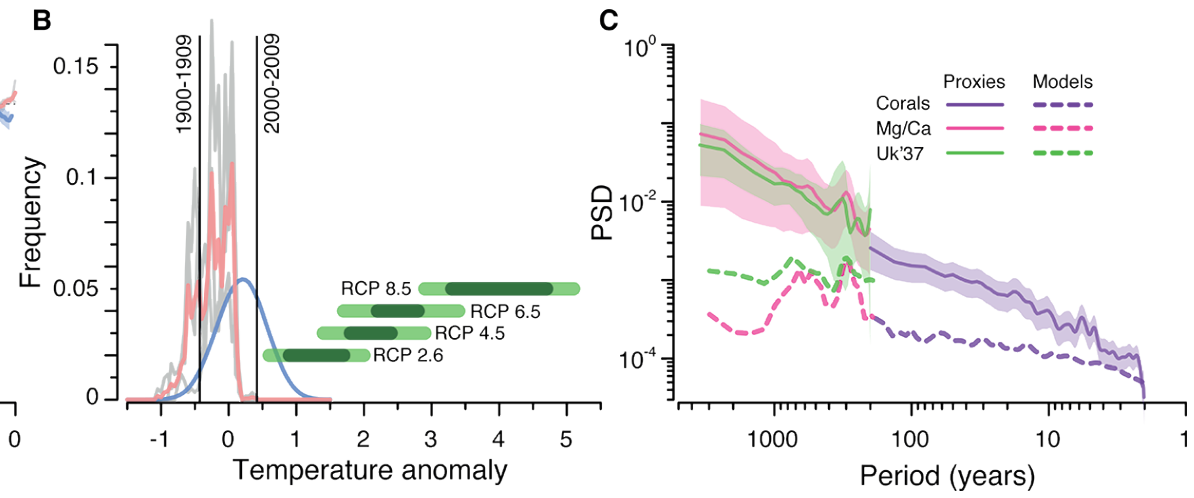

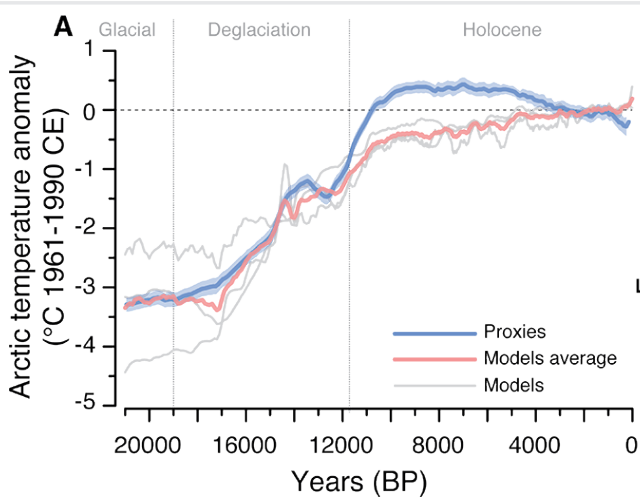

Figure 1: (A) Global mean temperature from proxies (Marcott et al. 2013; Shakun et al. 2012) and models (Liu et al. 2014). (B) Histograms of the Holocene time series in (A) showing how the distribution of Holocene temperatures compare to the $20^{\text {th }}$ century instrumental range and IPCC projections for 2100 (Collins et al. 2014 ). (C) Power Spectral Density (PSD) of sea surface temperature for Holocene time series (Laepple and Huybers 2014). RCP = Representative Concentration Pathway. 